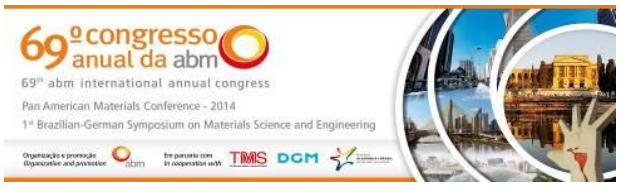

Tema: Fundição

\title{
CARACTERIZAÇÃO MICROESTRUTURAL DA INTERFACE DE TUBO BIMETÁLICO CENTRIFUGADO*
}

\author{
João Guilherme Dessi ${ }^{1}$ \\ Antônio Rafael Andrade ${ }^{2}$ \\ Conrado Ramos Moreira Afonso ${ }^{3}$
}

\section{Resumo}

Neste trabalho estudou-se a microestrutura e a interface de um tubo bimetálico cladeado por centrifugação, constituído externamente em aço API 5L X65Q e internamente pela superliga de $\mathrm{Ni}$-Cr Inconel 625, ambos vazados pela mesma posição relativa no tubo. O vazamento do Inconel 625 causou erosão no aço que diminuiu de intensidade do lado de vazamento (região mais quente) para a o lado oposto (região mais fria), onde a região de interdifusão não se apresentou mesmo uniforme. Nas regiões mais quentes (lado vazado e meio do tubo) ocorreu o cladeamento completo, com uma interface continua entre ambos os materiais constituintes, enquanto que na região mais fria a interface apresentou descontinuidades. $\mathrm{O}$ aço apresentou microestrutura ferrítica-perlítica com a região adjacente a interface descarbonetada, com grãos ferriticos nanométricos em uma região estreita de 3 $\mu \mathrm{m}$. O Inconel 625 apresentou uma microestrutura de dentritas de austenita Ni-cfc com fases de Laves interdentríticas, devido a aumento do teor de Fe, com alta densidade de discordâncias na região adjacente a interface livre de precipitados.

Palavras-chave: Fundição centrífuga; Tubos bimetálicos; Cladeamento;

\section{INTERFACE MICROSTRUCTURAL CHACARCTERIZATION OF CENTRIFUGAL- CAST BIMETALLIC PIPE}

\begin{abstract}
In this work, the microstructure and the interface of a clad bimetallic tube by centrifugal casting, consisting externally in steel API 5L X65Q steel and internally by Ni-Cr superalloy Inconel 625, both poured in the same relative position in the pipe. The pouring of Inconel 625 caused erosion in the steel, decreasing the steel thickness from the pouring side (hotter region) to the opposite side (the coldest region) where the interdiffusion region was not uniform. In hotter regions (pouring side and middle of the pipe), a complete cladding occurred, with a continuous interface between the two constituent materials, while the coldest region in the interface presented discontinuities. The steel presented a ferrite-pearlite microstructure, with the region adjacent the interface decarburized, and ferritic nanosized grains in a narrow region $3 \mu \mathrm{m}$ away from the interface. The Inconel 625 showed a microstructure of Ni-fcc austenite dendrites with interdendritical Laves phases, due to the increased Fe content in the Inconel 625, with high dislocation density in the free-precipitated region adjacent to the interface.
\end{abstract}

Keywords: Centrifugal casting; Bimetallic pipes; Cladding.

1 Eng. ${ }^{\circ}$, Universidade Federal de São Carlos, Programa de Pós-graduação em Ciência e Engenharia de Materiais.

2 M.Sc, ENGEMASA Engenharia e Materiais LDTA, Laboratório de Desenvolvimento e Controle de Processos.

3 Prof. Dr., Universidade Federal de São Carlos, Departamento de Engenharia de Materiais.

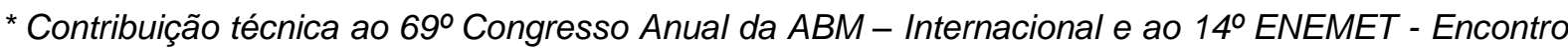
Nacional de Estudantes de Engenharia Metalúrgica, de Materiais e de Minas, 21 a 25 de julho de 2014, São Paulo, SP, Brasil.
} 


\section{INTRODUÇÃO}

$\mathrm{Na}$ indústria de óleo e gás, ligas resistentes à corrosão frequentemente necessitam serem empregadas na fabricação de tubulações, tanto para aplicações onshore, quanto offshore. O uso racional de materiais se faz necessário de forma a reduzir-se custos e otimizar o uso de materiais de custo mais elevados, sem que ocorra perdas de desempenho e funcionalidade $[1,2]$.

Um exemplo deste uso racional são os tubos bimetálicos lined (unidos mecanicamente) e cladeados (unidos metalurgicamente). Estes tubos são fabricados, externamente, em um aço alta resistência baixa liga (ARBL) chamado de backing steel, que confere resistência mecânica e tenacidade ao tubo e internamente em uma liga resistente à corrosão (Corrosion resistent alloy - CRA), que em contato com o fluido a ser transportado não sobre corrosão e degradação extensa como o aço ARBL, isolando também este do contado deste com o fluido [2]. Nos tubos cladeados a ligação entre os materiais constituintes é metalúrgica, de forma que uma camada de interdifusão mútua na interface entre os materiais se faz presente. Um tubo cladeado deve então apresentar esta camada de interdifusão em uma interface sem descontinuidades e com mínima mistura possível do material do backing steel na CRA [3].

A fundição centrifuga é uma técnica tradicional de produção de tubos sem costura (sem cordão de solda presente ao longo do comprimento deste), e consiste em vazar o metal líquido em um molde metálico cilíndrico em alta rotação, mantendo-a enquanto o metal solidifica. Tubos bimetálicos podem ser produzidos por meio de fundições centrífugas consecutivas, através de vazamento, centrifugação e solidificação do backing steel, seguido do vazamento, centrifugação e solidificação da CRA sobre o material da parte externa [4,5].

No presente trabalho foi avaliado um tubo bimetálico produzido por centrifugação, consistindo o externamente em aço ARBL da especificação API 5L X65Q, e internamente na liga resistente à corrosão Inconel 625, na condição bruta de fundição. Verificou-se o aspecto da interface em diferentes posições do tubo, interdifusão de elementos na interface, bem como o aspecto e a continuidade desta, além das microestruturas e fases obtidas.

\section{MATERIAIS E MÉTODOS}

O tubo bimetálico analisado foi produzido na ENGEMASA Engenharia e Materiais LDTA, localizada na cidade de São Carlos - SP, através de fundição por centrifugação. As ligas que iriam compor a parte externa (API 5L X65Q) e interna do tubo (Inconel 625) foram preparadas separadamente, e então foi vazado primeiramente o aço constituinte da parte externa, centrifugado. Após 40s, tempo suficiente para o tubo de aço solidificar-se, porém ainda, em alta temperatura, o Inconel 625 foi vazado pela mesma posição de vazamento do aço, centrifugado e solidificado internamente em contato com 0 aço. As cargas de cada liga foram calculadas de forma a se obter um tubo de diâmetro externo de $108 \mathrm{~mm}$ e espessura de $74 \mathrm{~mm}$ e comprimento de $2980 \mathrm{~mm}$. Em seguida, após a usinagem de acabamento, teve a espessura de parede reduzida para $12 \mathrm{~mm}$, de modo a eliminar na região mais interna os defeitos e inclusões que se concentram, posteriormente cortados eliminando $30 \mathrm{~cm}$ das extremidades do tubo pelo mesmo motivo. Seções anulares transversais do tubo de três posições (lado mais próximo ao local de vazamento, meio do tubo e lado oposto ao vazamento) foram retiradas para

\footnotetext{
* Contribuição técnica ao $69^{\circ}$ Congresso Anual da ABM - Internacional e ao 14ํㅡㄹ ENEMET - Encontro Nacional de Estudantes de Engenharia Metalúrgica, de Materiais e de Minas, 21 a 25 de julho de 2014, São Paulo, SP, Brasil.
} 


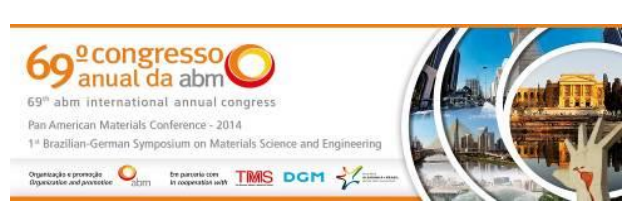

análises. As seções foram submetidas a ensaios de líquidos penetrantes e também atacadas para revelar sua macroestrutura. Após, amostras para microscopia óptica e de varredura foram retiradas das seções, embutidas em baquelite, lixadas em granulometrias sucessivamente menores, polidas em suspensão de alumina, com granulometria de $1 \mu \mathrm{m}$, e atacadas com Nital $2 \%$ para revelar a microestrutura do aço, ou em água régia para revelar o Inconel 625.

Tabela 1. Composições químicas das ligas constituintes do tubo bimetálico imediatamente antes do vazamento na centrífuga

\begin{tabular}{cccccccccccccccc}
\hline \multicolumn{11}{c}{ Elemento $(\% p)$} \\
\hline Liga & Fe & C & Si & Mn & P & S & Nb & Ti & V & Cr & Ni & Cu & Co & Al & Mo \\
\hline $\begin{array}{c}\text { API 5L } \\
\text { X65Q }\end{array}$ & Bal. & 0,17 & 0,31 & 0,96 & 0,018 & 0,010 & 0,009 & 0,004 & - & 0,09 & 0,07 & 0,02 & - & 0,004 & 0,017 \\
\hline $\begin{array}{c}\text { Inconel } \\
625\end{array}$ & 1,57 & 0,007 & 0,30 & 0,14 & 0,004 & 0,003 & 3,57 & 0,27 & 0,045 & 21,62 & Bal. & 0,04 & 0,11 & 0,17 & 9,26 \\
\hline
\end{tabular}

As análises de microscopia óptica foram realizadas em um microscópio ótico Olympus BX41M-LED e do sistema de processamento de imagens Infinity Capture acoplado. As análises de microscopia eletrônica de varredura (MEV) e EDS foram realizadas em microscópios Philips, modelo XL-30 FEG e FEl, modelo Inspect S50, ambos do Laboratório de Caracterização Estrutural (LCE) da UFSCar. As análises de EBSD/EDS foram realizadas em um microscópio MEV-FEG (feixe por emissão de campo), FEl modelo Nova NanoLab 600. A microscopia eletrônica de transmissão (TEM) foi feita através do equipamento FEI Tecnai G2 F20 (TEM/STEM) a 200kV com feixe por emissão de campo (FEG), acoplado à espectroscopia de energia dispersiva (EDS) EDAX. As amostras para a análise de TEM foram preparadas através de feixe de íons de Ga focalizado (FIB) in-situ através do método "lift-out" através de um equipamento Dual Beam FEI Nova 600 NANOLAB. Os perfis de microdureza foram medidos das amostras preparadas para microscopia ótica em um microdurômetro Shimadzu, modelo HMV-G 20ST, com carga aplicada de $300 \mathrm{gf}$. Três perfis foram medidos para cada amostra, a partir da superfície externa, percorrendo a espessura de parede do tubo em intervalos de $0,25 \mathrm{~mm}$, resultando em um perfil médio de durezas.

\section{RESULTADOS E DISCUSSÃO}

As seções transversais mais próximas do lado vazado e do meio do tubo apresentaram nos ensaio de líquidos penetrantes nenhuma descontinuidade na interface. Entretanto, a amostra mais próxima do lado oposto ao vazamento apresentou descontinuidades (Figura 1a). As macrografias das seções transversais (Figura 1b) revelaram a não uniformidade das espessuras relativas entre os materiais constituintes do tubo, com uma a espessura de parede do aço sendo menor próxima ao lado do vazamento (cerca de $4 \mathrm{~mm}$ ), aumentando ao longo do comprimento (cerca de $6 \mathrm{~mm}$ no meio e $8 \mathrm{~mm}$ próximo ao lado oposto).

\footnotetext{
* Contribuição técnica ao $69^{\circ}$ Congresso Anual da ABM - Internacional e ao 14ํㅡㄹ ENEMET - Encontro Nacional de Estudantes de Engenharia Metalúrgica, de Materiais e de Minas, 21 a 25 de julho de 2014, São Paulo, SP, Brasil.
} 

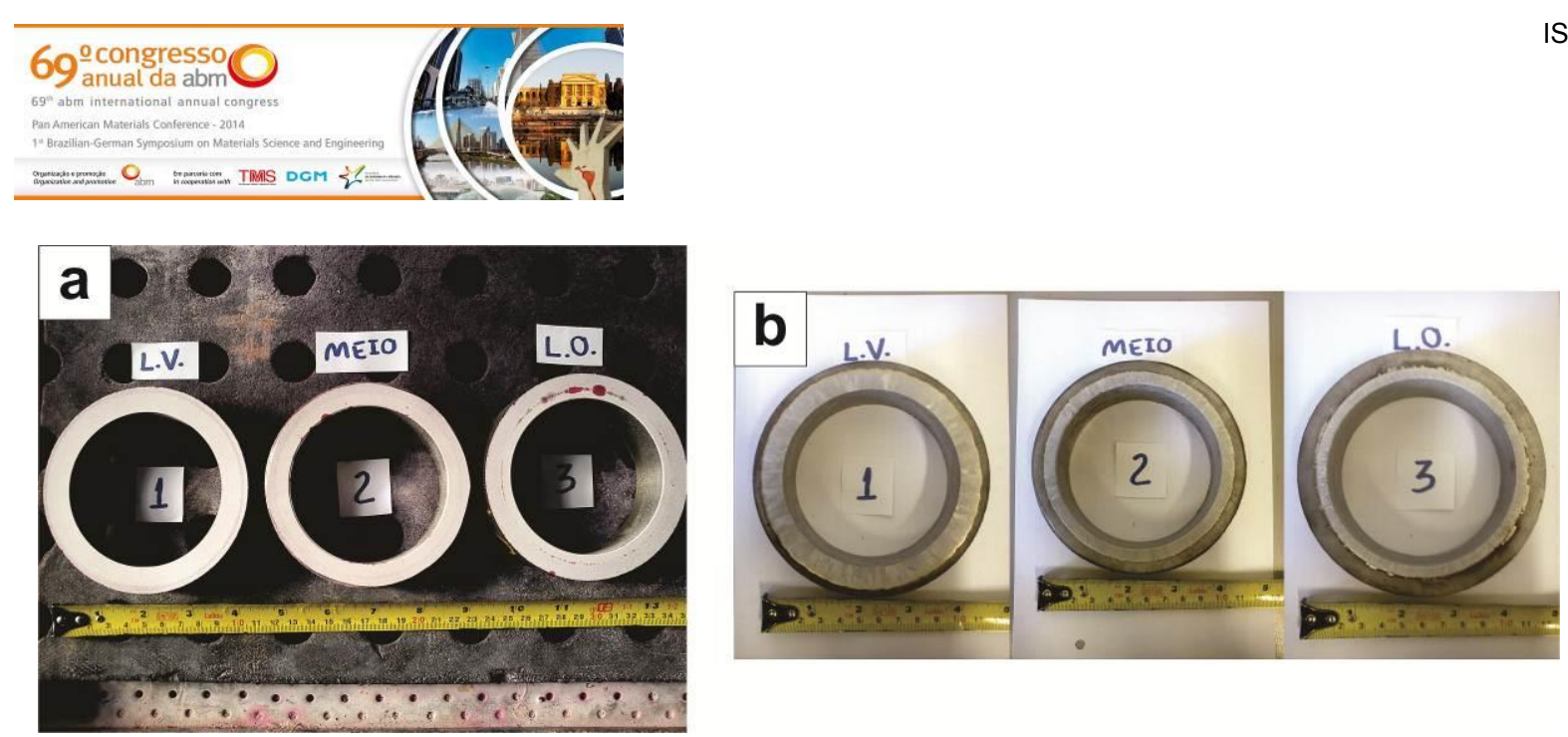

Figura 1. (a) Ensaios de líquidos penetrantes nas seções transversais das três posições analisadas. (b) Macrografias das mesmas amostras utilizadas nos ensaios de líquidos penetrantes, atacadas de forma a revelar a $C R A$. Ataque: Água régia a $80^{\circ} \mathrm{C}$.

As micrografias do tubo nas três regiões avaliadas, mostradas na Figura 2 mostram a microestrutura obtida no aço, constituindo de ferrita (Fe- $\alpha$ ) relativamente fina (micrométrica) e alongadas e perlita no interior dos grãos austeníticos que se solidificaram de forma colunar e em maiores dimensões. Este fato era esperado pela direcionalidade da extração e calor na centrifugação, ocorrendo na direção radial, da superfície externa (em contato com o molde) para a superfície interna

(Figura 3. (a) Micrografia revelando os grãos austeníticos com ferrita proeutetóide nos contornos, (b) imagem ampliada próxima ao contorno de grão austenítico e (c) microscopia eletrônica de varredura (MEV) mostrando uma colônia perlítica no aço. Ataque: Nital 2\%.(d) MEV mostrando as dendritas de austenita na CRA, com segregação e precipitação interdendrítica.

a)
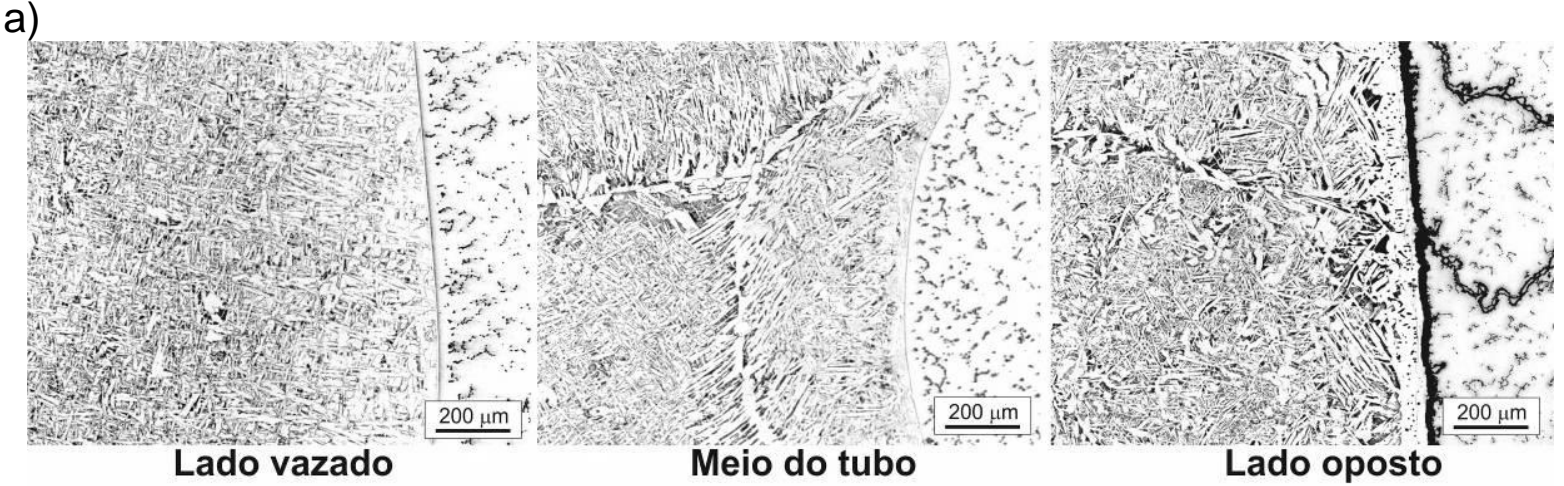

Figura 2. Micrografias das regiões da interface nas diferentes posições do tubo próximas à interface do tubo. Ataque: Nital $2 \%$.

O contorno de grão austenítico é possível de ser observado mesmo após a transformação eutetoíde, uma vez que a ferrita proeutetóide nucleou e cresceu nos contornos de grãos austeníticos, com morfologia de Widmanstatten, de forma a demarcá-los. No lado da $C R A$, a solidificação ocorreu também de forma colunar (Figura 2), uma vez, como foi possível observar pelas macrografias (Figura 1b), com a ocorrência de precipitados nos espaçamentos interdendríticos (em destaque na Figura 3.d), que ocorre a partir de cerca de $20 \mu \mathrm{m}$ da interface. Como revelado pelo ensaio de líquidos penetrantes, a interface do lado oposto apresentou descontinuidade ao longo da interface, juntamente com linhas de segregação ao próxima a interface.

\footnotetext{
* Contribuição técnica ao $69^{\circ}$ Congresso Anual da ABM - Internacional e ao 14ํㅡㄹ ENEMET - Encontro Nacional de Estudantes de Engenharia Metalúrgica, de Materiais e de Minas, 21 a 25 de julho de 2014, São Paulo, SP, Brasil.
} 

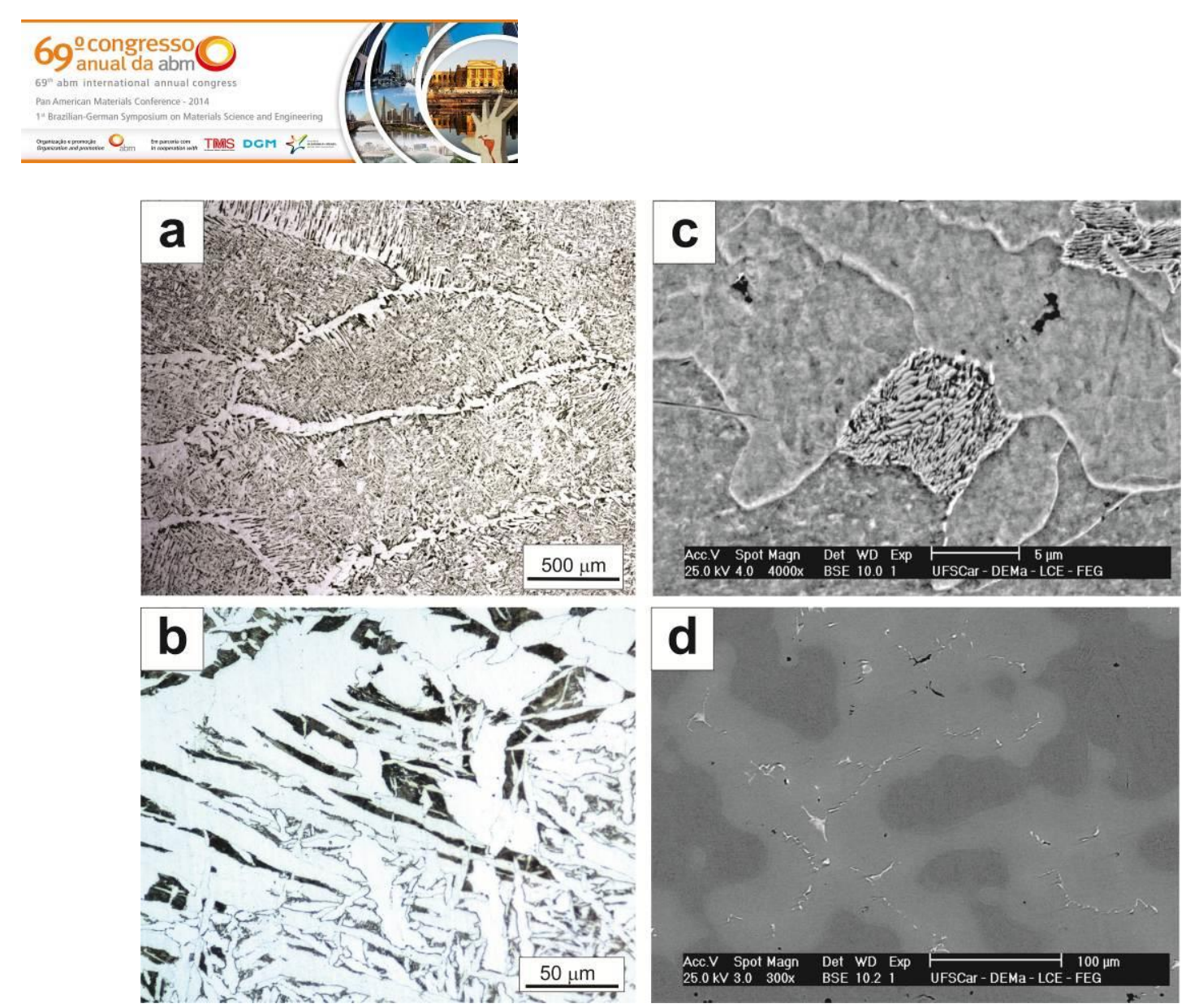

Figura 3. (a) Micrografia revelando os grãos austeníticos com ferrita proeutetóide nos contornos, (b) imagem ampliada próxima ao contorno de grão austenítico e (c) microscopia eletrônica de varredura (MEV) mostrando uma colônia perlítica no aço. Ataque: Nital 2\%.(d) MEV mostrando as dendritas de austenita na CRA, com segregação e precipitação interdendrítica.

Os perfis de microdureza médios ao longo da espessura do tubo, nas três posições avaliadas (Figura 3), mostraram uma variação considerável ao longo da espessura das diferentes posições no tubo. Esta variação deveu-se a variação da microestrutura ao longo da espessura, com as regiões no aço com ferrita mais fina e perlita sendo mais duras especialmente onde as colônias de perlita eram maiores, e mais baixa nos contornos dos grãos colunares, onde a ferrita proeutetóide se apresentam com maiores dimensões. Na região da CRA verificou-se também uma variação considerável na dureza ao longo da espessura devido a microestrutura, sendo menos duro nas regiões do seio das dendritas e mais duras nas regiões interdendríticas, especialmente onde havia maior concentração de precipitados. Os pontos mais próximos da interface em todas as posições se mostraram as regiões menos duras, na média, em todas as posições do tubo avaliadas. As regiões do aço adjacentes à interface com a CRA, destacadas ainda na Figura 3, apresentaram microestruturas nitidamente diferentes do restante da espessura: nestas regiões observa-se apenas ferrita (Fe- $\alpha$ ) poligonal com ausência de perlita. Está região empobrecida de carbonetos é relativamente pequena, com cerca de $50 \mu \mathrm{m}$ de espessura, e deve-se a difusão do carbono do aço, de maior teor, para a CRA, de menor teor de carbono, causando este empobrecimento próximo a interface.

A ausência de carbonetos e o menor teor de carbono da ferrita causam a diminuição da dureza nesta região. Sponseller et al [6] obteve resultado similiar na co-extrusão à quente de tubos de aço T11 e aço inoxidável 310, assim como Missori et al [7] na co-laminação à quente de aço A515 grau 6 e aço inoxidável AISI 304 L. A menor dureza apresentada foi na amostra do lado oposto ao vazamento onde ocorreu a descontinuidade na interface. Entretanto, nesta mesma amostra a dureza da CRA na região adjacente na interface foi a maior que nas outras amostras, que

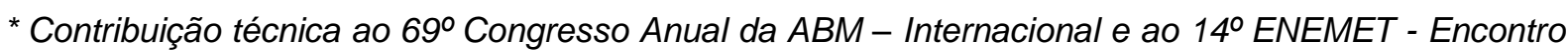
Nacional de Estudantes de Engenharia Metalúrgica, de Materiais e de Minas, 21 a 25 de julho de 2014, São Paulo, SP, Brasil.
} 


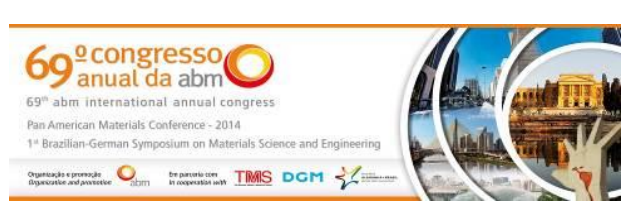

apresentaram durezas próximas. Esta região da amostra do lado aposto ao vazamento é justamente onde foi observado linhas de segregação, que aumentaram a dureza média da liga nesta região.

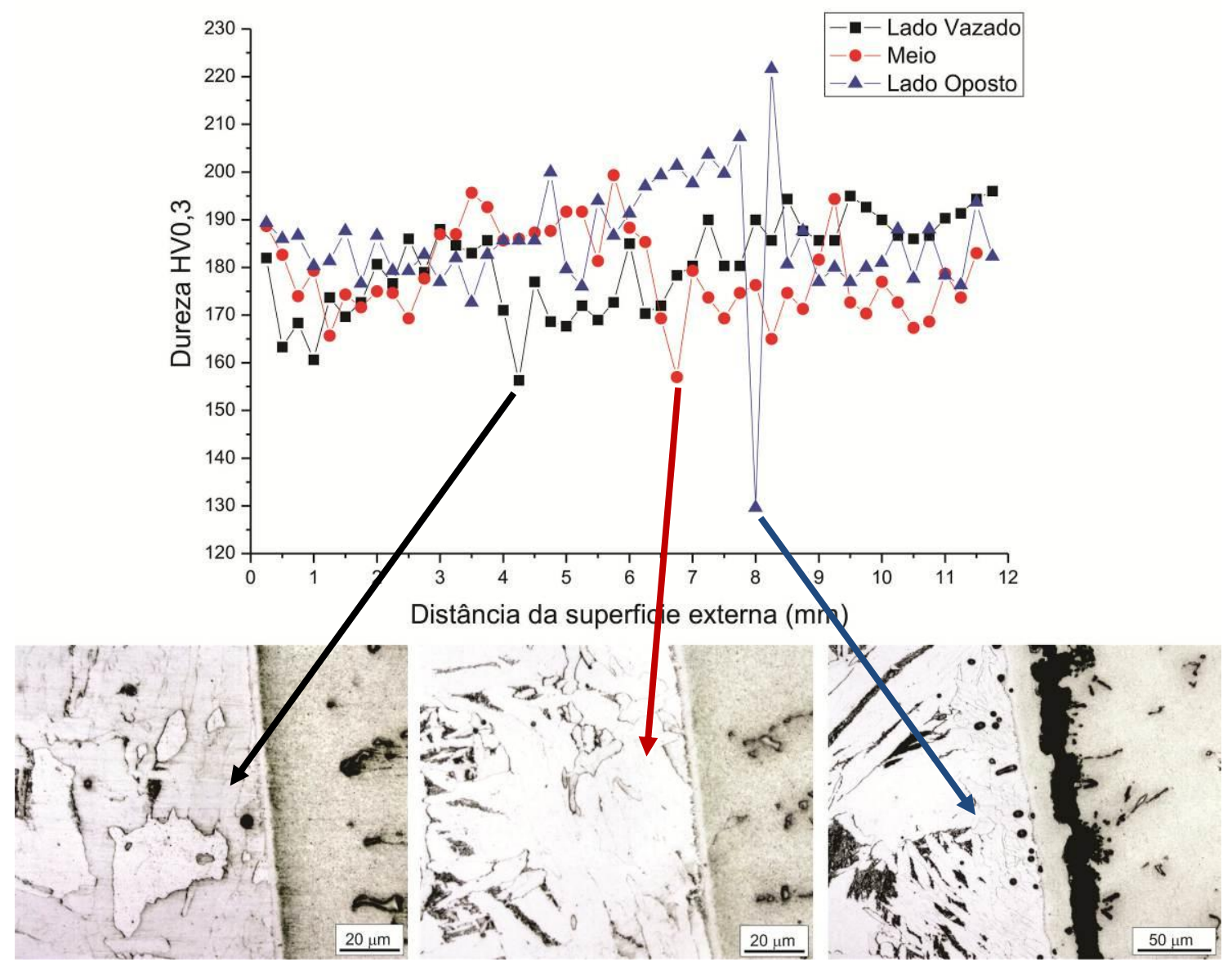

Figura 4. Perfil de microdureza ao longo da espessura do tubo em três diferentes posições: próximo ao lado vazado, no meio do comprimento do tubo, e no lado oposto. Em destaque as microestruturas das regiões próximas à interface.

Através de análises EDS, realizados por microscopia eletrônica de varredura (MEV) verificou-se que o teor de Fe na CRA aumentou bastante (Tabela 2), excedendo inclusive o limite especificado para o teor deste elemento, confirmando que houve de fato extensa erosão e diluição do aço na CRA, como evidenciado na macrografia (Figura 1 a), pela não uniformidade das espessuras relativas entre o aço e a CRA ao longo do comprimento do tubo.

Tabela 2. Análise semi-quantitativa de EDS do CRA em diferentes posições do tubo

\begin{tabular}{lcccc}
\hline Posição & $\mathrm{Fe}(\% \mathrm{p})$ & $\mathrm{Cr}(\% \mathrm{p})$ & $\mathrm{Ni}(\% \mathrm{p})$ & $\mathrm{Mo}(\% \mathrm{p})$ \\
\hline Lado Vazado & $15,0 \pm 0,4$ & $19,2 \pm 0,4$ & $58,2 \pm 0,6$ & $7,6 \pm 0,5$ \\
\hline Meio do tubo & $20,0+0,6$ & $17,9+0,6$ & $55,37+0,9$ & $6,8+0,7$ \\
\hline Lado oposto & $15,7 \pm 0,3$ & $19,2 \pm 0,3$ & $58,7 \pm 0,4$ & $6,5 \pm 0,4$ \\
\hline
\end{tabular}

Através das análises de EDS pode-se também traçar o perfil de composição relativa dos principais elementos de liga ( $\mathrm{Fe}, \mathrm{Cr} \mathrm{Ni}$ e $\mathrm{Mo}$ ) na região próxima à interface nas três posições do tubo (Figura 4). Nas amostras do lado vazado e do meio do tubo verificou-se que a camada de interdifusão é bastante estreita, com cerca de $5 \mu \mathrm{m}$ de

\footnotetext{
* Contribuição técnica ao 69ำ Congresso Anual da ABM - Internacional e ao 14ํㅡㄹ ENEMET - Encontro Nacional de Estudantes de Engenharia Metalúrgica, de Materiais e de Minas, 21 a 25 de julho de 2014, São Paulo, SP, Brasil.
} 


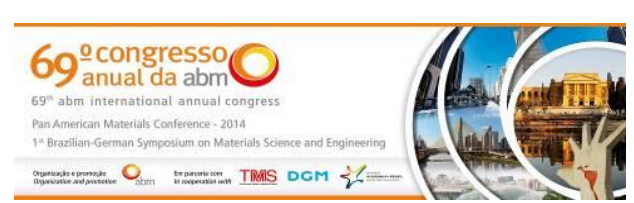

espessura, porém com os perfis dos elementos apresentando variações na distribuição, em especial o Fe. Este é um indicativo de que distribuição e temperaturas ao longo do tubo, durante a solidificação foi desigual, sendo mais quente na posição do vazamento e diminuindo-se ao longo do comprimento, sendo mais frio então no lado oposto. Pelos perfis de concentração pode-se verificar também que a descontinuidade não ocorreu de fato na interface, mas em uma região adjacente a esta, na região da CRA, à cerca de 20-25 $\mu \mathrm{m}$ da interface. Observa-se também que próximos aos precipitados interdendríticos, em destaque na Figura 5, a concentração de Mo medida por EDS na Figura 4 foi maior.
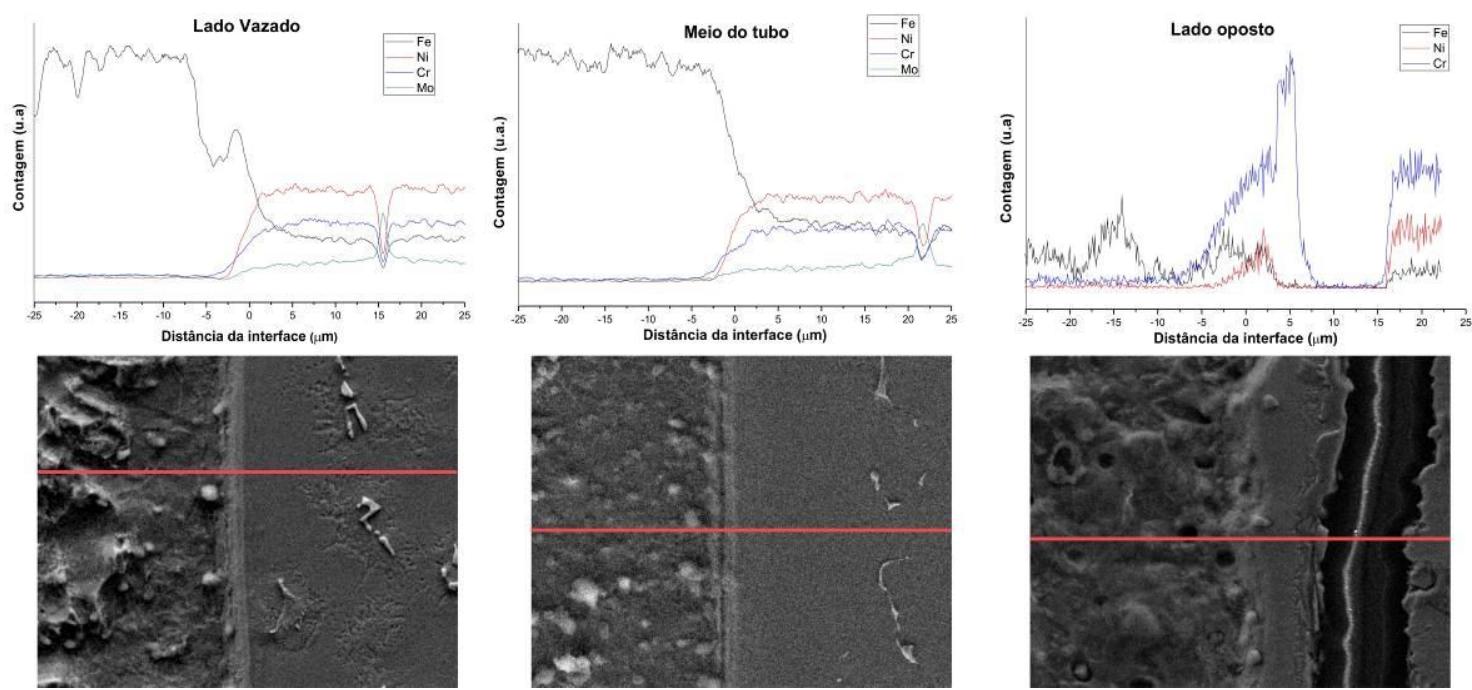

Figura 5. Perfis de concentração relativa dos elementos principais próximos à interface, determinados por EDS. A largura da imagem de MEV $=56 \mu \mathrm{m}$.

Ao se observar melhor os precipitados, verificou-se que de fato eles estão presentes apenas nos espaçamentos interdentríticos, sendo ricos, em sua composição de Mo e Nb. Estes são semelhantes aos observados por Silva et al.[8] e Rajani et al.[9] em soldas de Inconel 625, que ambos concluíram se tratarem de fase de Laves. Segundo Floreen et al.[10], durante a solidificação do Inconel 625, ocorre a rejeição de Mo e Nb para os espaçamentos interdendríticos, levado a precipitação de fase de Laves e $\mathrm{NbC}$. Não foi observado $\mathrm{NbC}$ nas amostras do tubo bimetálico, entretanto ainda em Floreen et al. é apresentado que o aumento da concentração de Fe no Inconel 625 desloca o diagrama ternário na direção da formação da fase de Laves em detrimento da formação de $\mathrm{NbC}$.

\footnotetext{
* Contribuição técnica ao $69^{\circ}$ Congresso Anual da ABM - Internacional e ao 14ํㅡㄹ ENEMET - Encontro Nacional de Estudantes de Engenharia Metalúrgica, de Materiais e de Minas, 21 a 25 de julho de 2014, São Paulo, SP, Brasil.
} 
aço. Pelo EDS observa-se que as regiões, nas quais houve essa mudança estrutural, não apresentaram níquel em sua composição.

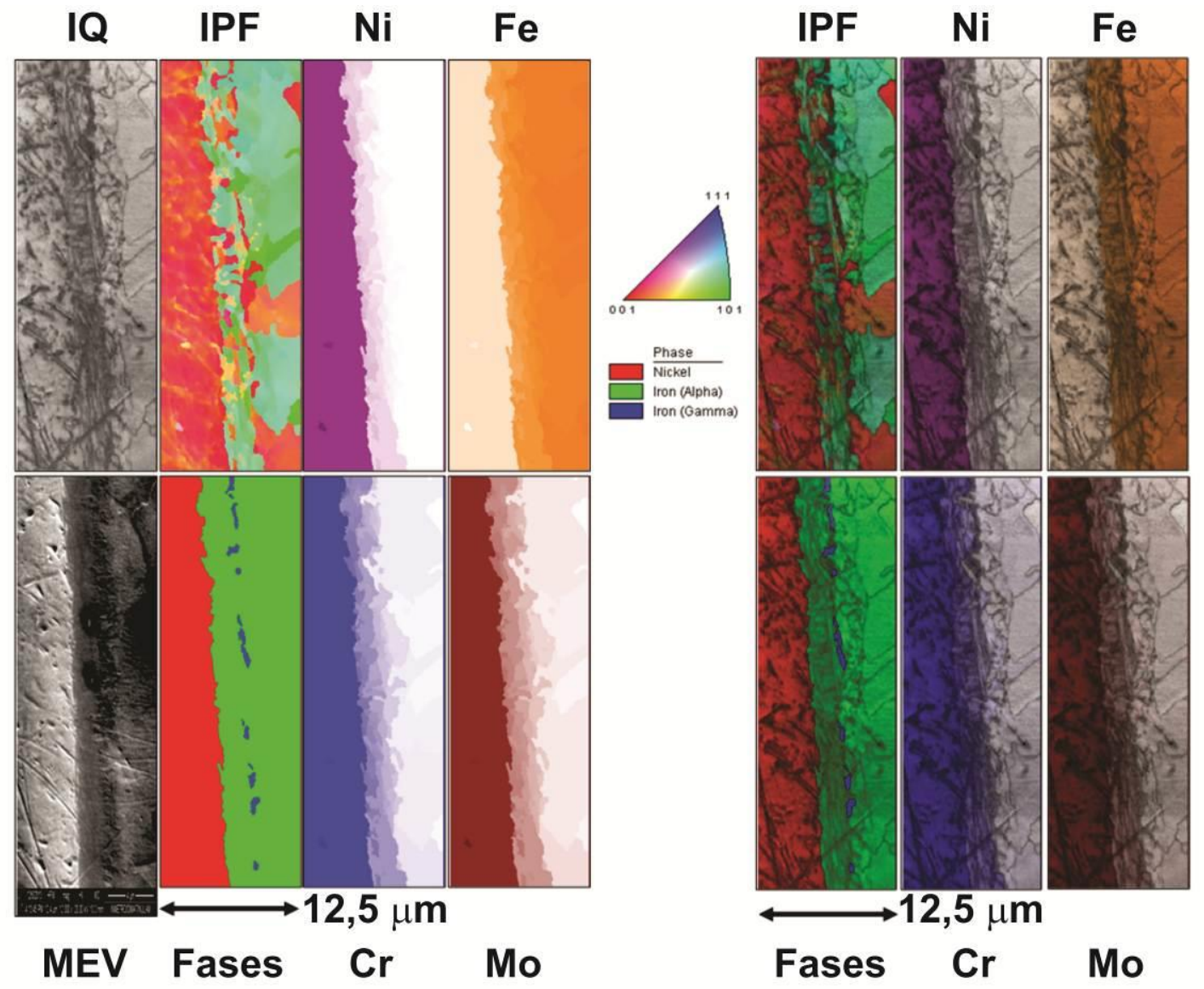

Figura 7. Análise de EBSD da amostra do meio do tubo: IQ - Image quality, IPF - Figura de polos inversos, MEV - imagem de varredura, mapeamento de fases e EDS dos principais elementos constituintes, à esquerda. À direita, as imagens das análises foram sobrepostas ao mapa IQ.

A Figura 7 a seguir ilustra micrografias de microscopia eletrônica de transmissão (TEM) da amostra preparada por feixe de íons de Ga focalizado (FIB) mostrando detalhe da interface (amostra do meio do tubo) da CRA (à esq.) e o aço (à dir.). A Figura 7a mostra uma imagem de STEM (microscopia eletrônica de transmissão por varredura) com detector de campo escuro anular (ADF) e a visão geral da amostra. $O$ detalhe da interface e o lado do aço podem ser observados na Figura 7b, detalhes da interface e do lado CRA mostrando alta densidade de discordâncias são mostrados nas Figuras $8 c$ e $7 d$, respectivamente. Pode-se confirmar a presença de grãos bastantes finos adjacentes à interface no lado do aço, observados nas análises de EBSD sendo seguidos de grão maiores, vistos na camada descarbonetada. Na região adjacente à interface no lado do CRA apresentou maior densidade de discordâncias, devidas provavelmente a contração térmica diferencial entre ambos os materiais, levando a uma deformação plástica localizada na interface. Esta deformação pode ser a razão da descontinuidade observada na região mais fria (lado oposto), onde devido a temperatura mais baixa não houve interdifusão uniforme e conferindo boa ligação metalurgia entre os materiais.

$\mathrm{Na}$ interface lado vazado (onde houve uma maior erosão), conforme mostra a Figura 8 estão representadas pelas micrografias de STEM-ADF. A amostra da interface entre a CRA (à esq.) e o aço (à dir.) são ilustradas através da Figura 9.a

* Contribuição técnica ao 69 Congresso Anual da ABM - Internacional e ao 14ํㅡㄹ ENEMET - Encontro Nacional de Estudantes de Engenharia Metalúrgica, de Materiais e de Minas, 21 a 25 de julho de 2014, São Paulo, SP, Brasil. 


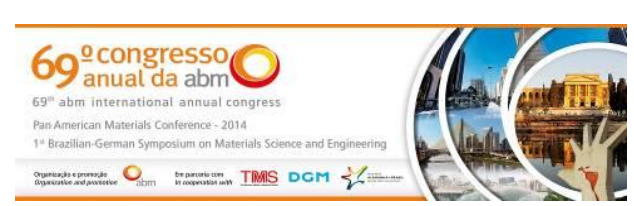

com uma visão geral da amostra e na Figura $8 \mathrm{~b}$ em maior detalhe a microestrutura da interface, que apresentou características semelhantes a região do meio do tubo, com uma região de grãos também mais finos adjacentes à interface.
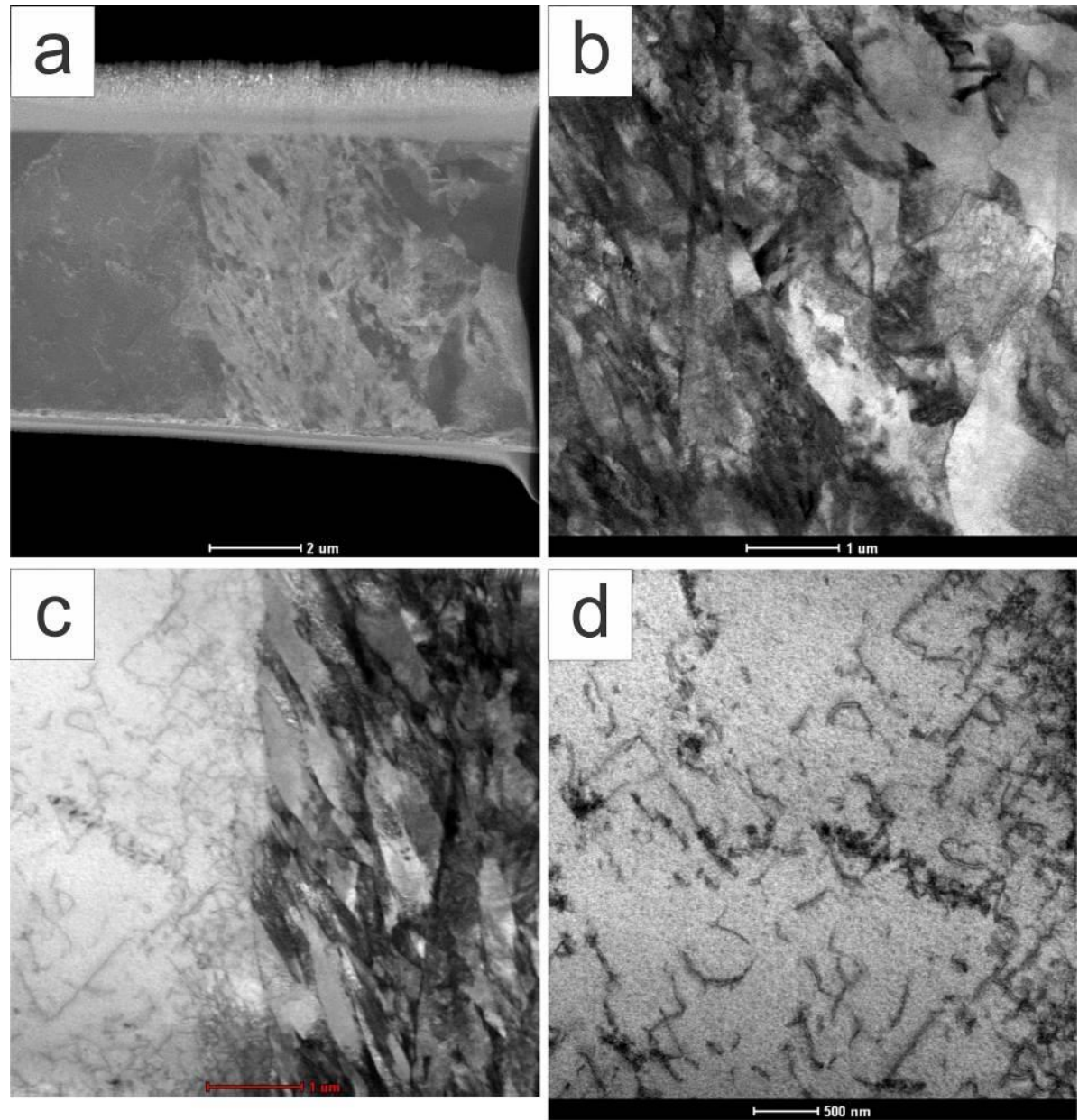

Figura 8. Micrografias de TEM da amostra preparada por FIB mostrando em detalhe a interface (meio do tubo) entre a CRA (esq.) e o aço (dir.): (a) imagem de STEM com detector de campo escuro anular (ADF) e a visão geral da amostra. (b) detalhe da interface e o lado do aço, (c) detalhe de interface e (d) detalhe do lado da CRA mostrando concentração de discordâncias.
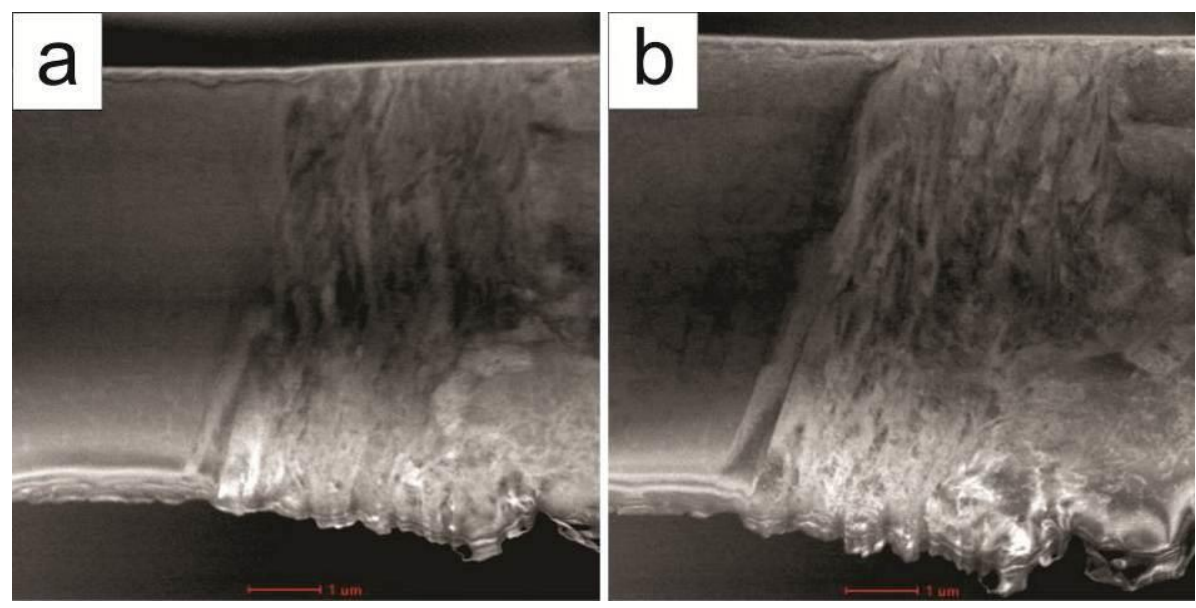

Figura 9. Micrografias de STEM com detector de campo escuro anular (ADF) da amostra da interface (lado vazado do tubo) entre CRA (esq.) e o aço (dir.): (a) visão geral da amostra. (b) e em detalhe da interface.

\footnotetext{
* Contribuição técnica ao 69 Congresso Anual da ABM - Internacional e ao 14ํㅡㄹ ENEMET - Encontro Nacional de Estudantes de Engenharia Metalúrgica, de Materiais e de Minas, 21 a 25 de julho de 2014, São Paulo, SP, Brasil.
} 


\section{CONCLUSÃO}

A elevada temperatura de vazamento da CRA promoveu erosão excessiva no aço, que diminui ao longo do comprimento, e na região mais fria do lado oposto, ocorreram descontinuidades próximas a interface, no lado da CRA. O aço apresentou uma microestrutura ferrítica-perlítica, enquanto a CRA apresentou uma microestrura dendrítica de $\mathrm{Ni}-\gamma$ (cfc) com fase de Laves, formadas nos espaços interdendríticos, ricos em $\mathrm{Mo}$ e $\mathrm{Nb}$. A erosão elevou o teor de $\mathrm{Fe}$ na CRA, aumentando a proporção de fases de Laves presentes em detrimento da formação de $\mathrm{NbC}$. A região do aço próxima à interface com a CRA apresentou descarbonetação, devido à difusão de carbono para a CRA, e consequente queda de dureza. Em uma região de $3 \mu \mathrm{m}$ de espessura adjacente à interface da amostra foram encontrado grãos ferríticos nanométricos, com alta desordem cristalina destes grão em relação ao restante, indicando que na interface ocorreu solidificação bastante rápida. No lado da CRA adjacente a interface foi observada uma elevada densidade de discordâncias devida, provavelmente, à contração térmica diferencial dos materiais, a qual promoveu pequena deformação plástica. Na região oposta ao lado do vazamento a fratura provavelmente ocorreu devido a menor ligação metalúrgica obtida, ocasionada pela menor temperatura, que não resistiu à deformação advinda da contração. De forma a evitar a erosão excessiva e melhor distribuição de temperatura durante a solidificação e uma interface contínua em toda a extensão do tubo, as temperaturas de vazamento da CRA, do tubo de aço já solidificado devem ser melhores controladas, além das posições relativas entre os vazamentos das ligas.

\section{Agradecimentos}

Os autores agradecem ao INMETRO-RJ, em nome do pesquisador Braulio Soares Archanjo pela preparação das amostras por FIB e pelas análises de EBSD, ao Laboratório de Caracterização Estrutural (LCE-UFSCar) pelas análises de MEV e TEM, à ENGEMASA Engenharia e Materiais Ltda. pelo apoio com o fornecimento de materiais, fusão e pela centrifugação do tubo bimetálico, pela disponibilidade de seus laboratórios e equipamentos. Agradecem também ao Programa de PósGraduação em Ciência e Engenharia de Materiais (PPG-CEM/UFSCar), Conselho Nacional de Pesquisa e Desenvolvimento - CNPq, pelo suporte financeiro através da bolsa de mestrado.

\section{REFERÊNCIAS}

1 Smith L. Engineering with Clad Steel. $2^{\underline{a}}$ edition. Nickel Development Institute, Technical Series No. 10064, 2012.

2 Smith L, Celant M. CASTI Handbook of Cladding Technology. 2a edição. Edmonton: CASTI Publications Inc; 2000.

3 American Petroleum Institute. API 5LD: Specification for CRA Clad or Lined Steel Pipe (3rd edition), 2009.

4 Janco N. Centrifugal Casting. Schaumburg: American Foundry Society; 1988.

5 Yoshitake A, Torigoe T. Centrifugally Cast Bimetallic Pipe for Offshore Corrosion Resistant Pipelines. Proceedings of the $4^{\text {th }}$ International Offshore and Polar Engineering Conference. Osaka, Japan. April 10-15, 1994.

\footnotetext{
* Contribuição técnica ao $69^{\circ}$ Congresso Anual da ABM - Internacional e ao 14ํㅡㄹ ENEMET - Encontro Nacional de Estudantes de Engenharia Metalúrgica, de Materiais e de Minas, 21 a 25 de julho de 2014, São Paulo, SP, Brasil.
} 
6 Sponseller DL. Timmons GA. Bakker WT. Development of clad boiler tubes extruded from bimetallic centrifugal castings. Journal of Materials Engineering and Performance. 1998; 7(2): 227-238.

7 Missori S, Murdolo F, Sili, A. Microstructural characterization of a Stainless-cladded Carbon-steel. Metallurgical Science and Technology. 2001; 19(2): 21-24

8 Silva CC, Afonso, CRM, Ramirez AJ, Motta, MF, Miranda HC, Farias, JP. Aspectos Metalúrgicos de Revestimentos Dissimilares com a Superliga à Base de Níquel Inconel 625. Soldagem \& Inspeção. 2012; 17(3): 251-263.

9 Rajani HRZ, Mousavi SAAA, Sani FM. Comparison of corrosion behavior between fusion cladded and explosive cladded Inconel 625/plain carbon steel bimetal plates. Materials and Design. 2013:43:467-474.

10 Floreen S, Fuchs, GE. Yang WJ. The Metallurgy of Alloy 625. Superalloys 718, 625, 706 and Various Derivatives. Superalloys Conference Proceedings. 1994: 13-37.

* Contribuição técnica ao 69ำ Congresso Anual da ABM - Internacional e ao 14ํㅡㄹ ENEMET - Encontro Nacional de Estudantes de Engenharia Metalúrgica, de Materiais e de Minas, 21 a 25 de julho de 2014, São Paulo, SP, Brasil. 